\title{
THE EFFECTS OF Mo0 3 POWDER LUBRICATION ON TRIBOLOGICAL PROPERTIES OF SLIDING PAIR EXPOSED TO HIGH TEMPERATURE
}

The effect of molybdenum trioxide $\mathrm{MoO}_{3}$ powder on the tribological properties of sliding pair exposed to the temperature up to $700{ }^{\circ} \mathrm{C}$ was examined. The experiment showed that $\mathrm{MoO}_{3}$ powder placed directly on the sliding surface of main tribological body influenced and reduced friction values of tested materials. Especially in a temperature range from 500 to $700{ }^{\circ} \mathrm{C}$ a clear minimum of friction coefficient around $600{ }^{\circ} \mathrm{C}$ was observed. The X-ray diffraction analysis of friction and wear tracks that appeared on specimens showed mixture of different elements which are the product generated during tribological processes at high temperature.

Keywords: aluminium bronze, molybdenum trioxide, high temperature, $\mathrm{Cu}_{3} \mathrm{Mo}_{2} \mathrm{O}_{9}$, solid lubricant

\section{Introduction}

In this experimental work the tribological properties of solid lubricant coated stainless steel in contact with aluminium bronze under high temperature condition were studied. It is one of the capable materials which can be used at high temperature because of their thermal stability up to around $300{ }^{\circ} \mathrm{C}$. However, at the temperature of over $400{ }^{\circ} \mathrm{C}$, high friction coefficient and poor wear resistance are noted that why their lubricity properties are required to be further improved. On the other hand, the lubricity of many kinds of metal oxide at high temperature was studied. It was reported that $\mathrm{MoO}_{3}$ showed superior lubricity at high temperature of about $700{ }^{\circ} \mathrm{C}[1]$, therefore it was expected that $\mathrm{MoO}_{3}$ layer placed on the active friction surface enhances friction properties of aluminium bronze at high temperature.

\section{Material and Sample Description}

\subsection{Molybdenum Trioxide $\mathrm{MoO}_{3}$}

Molybdenum trioxide $\mathrm{MoO}_{3}$ is chemical compound. This compound is produced on the largest scale of any molybdenum compound. It occurs as the rare mineral molybdite. Its chief application is as an oxidation catalyst and as raw material for production of molybdenum metal. The oxidation state of molybdenum in this compound is +6 [2]. $\mathrm{MoO}_{3}$ is produced industrially by burning molybdenum disulfide, the chief ore of molybdenum:

$$
2 \mathrm{MoS}_{2}+7 \mathrm{O}_{2} \rightarrow 2 \mathrm{MoO}_{3}+4 \mathrm{SO}_{2} .
$$

The laboratory synthesis entails the acidification of aqueous solutions of sodium molybdate with perchloric acid [3]

$$
\begin{aligned}
& \mathrm{Na}_{2} \mathrm{MoO}_{4}+\mathrm{H}_{2} \mathrm{O}+2 \mathrm{HClO}_{4} \rightarrow \\
& \rightarrow \mathrm{MoO}_{3}\left(\mathrm{H}_{2} \mathrm{O}\right)_{2}+2 \mathrm{NaClO}_{4} .
\end{aligned}
$$

The dihydrate loses water readily to give the monohydrate. Both are bright yellow in colour. Molybdenum trioxide dissolves slightly in water to give "molybdic acid." In base, it dissolves to afford the molybdate anion [2]. In the gas phase, three oxygen atoms are double bonded to the central molybdenum atom. In the solid state, anhydrous $\mathrm{MoO}_{3}$ is composed of layers of distorted $\mathrm{MoO}_{6}$ octahedra in an orthorhombic crystal. The octahedra share edges and form chains which are cross-linked by oxygen atoms to form layers. The octahedra have one short molydenum-oxygen bond to a non-bridging oxygen [4]. Molybdenum trioxide has widespread industrial use. Its major use is as an additive to steel and other corrosion-resistant alloys. It is also used in the production of molybdenum products, as an industrial catalyst, a pigment, a crop nutrient, a component of glass, ceramics and enamels, a flame retardant for polyester and polyvinyl chloride resins, and as a chemical reagent. [5] Because of $\mathrm{MoO}_{3}$ layered structure (see Fig. 1) $\mathrm{MoO}_{3}$ is of interest for intensive tribological experimental investigations conducted at elevated and high temperatures. Physical and chemical properties are listed in Table 1.

Fig. 2 shows SEM image of $\mathrm{MoO}_{3}$ powder used in experimental investigation of friction properties for the tribological pair composed of coated stainless steel specimen rubbed against aluminium bronze.

\footnotetext{
* Yoshinori Takeichi ${ }^{1}$, Marian Dzimko ${ }^{2}$, Uwe Winkelmann ${ }^{3}$

${ }^{1}$ Department of Mechanical Engineering, Toyohashi University of Technology, Toyohashi Aichi, Japan, E-mail: takeichi@mech.tut.ac.jp

${ }^{2}$ Faculty of Mechanical Engineering, Department of Design and Machine Elements, University of Zilina, Slovakia

${ }^{3}$ Institute for Mechanical Engineering (IfM), University of Applied Sciences Magdeburg-Stendal, Magdeburg, Germany
} 


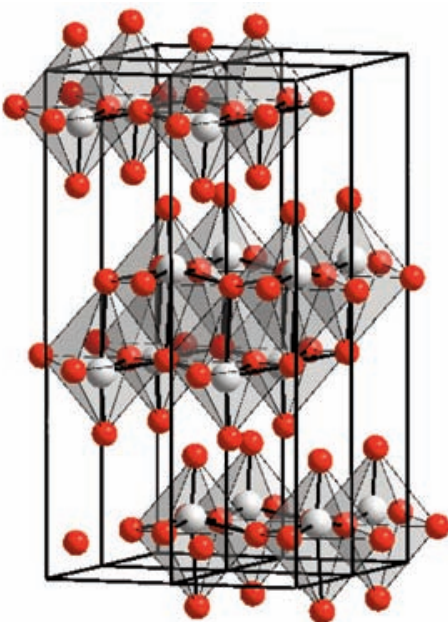

Fig. 1 Crystal structure of $\mathrm{MoO}_{3}[2,5]$

Physical and chemical properties

Table 1

\begin{tabular}{|l|l|}
\hline Appearance & White or slightly yellow to slightly bluish powder \\
\hline Odour & Odourless \\
\hline Solubility & $0.107 \mathrm{~g} / 100 \mathrm{~g}$ water $@ 18{ }^{\circ} \mathrm{C}$ \\
\hline Density & $4.69 \mathrm{~g} / \mathrm{cm}^{3}$, solid \\
\hline Boiling Point & $1150{ }^{\circ} \mathrm{C}$ \\
\hline Melting Point & $795^{\circ} \mathrm{C}$ begins to sublime at $700{ }^{\circ} \mathrm{C}$ \\
\hline Crystal structure & Orthorhombic \\
\hline
\end{tabular}

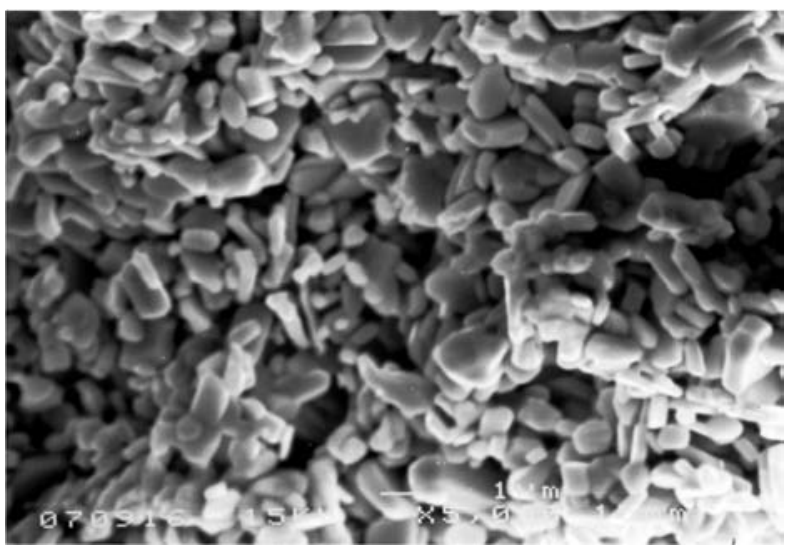

Fig. 2 SEM image of $\mathrm{MoO}_{3}$ powder

\subsection{Aluminium Bronze}

Aluminium bronze, C6191 (JIS H 3250, Japanese Industrial Standards), with excellent fatigue resistance, corrosion resistance and wear resistance was chosen as material under test. The compositions of C6191 are shown in Table 2. It is copper based alloy which includes about $10 \%$ aluminium and 3 to $5 \%$ iron.
Compositions of aluminium bronze $\mathrm{C} 6191$

Table 2

\begin{tabular}{|c|c|c|c|c|c|}
\hline Content & $\mathrm{Cu}$ & $\mathrm{Al}$ & $\mathrm{Fe}$ & $\mathrm{Mn}$ & $\mathrm{Ni}$ \\
\hline Dens. $\%$ & $81-88$ & $8.5-11$ & $3-5$ & $0.5-2$ & $0.5-2$ \\
\hline
\end{tabular}

\subsection{Stainless Steel}

Stainless steel, SUS304 (JIS G 4303) was used as a counterpart material for the friction test.

\section{Specimens}

It is well known that the oxide powders are difficult to adhere to metal surface. In the case of executed experiments the sample preparation was done as follows.

1. The sliding nominal surface of specimen was polished and then slightly sandblasted. The surface roughness $(R a)$ was measured with values around $1.0 \mu \mathrm{m}$.

2. The specimen was put into a glass container filled with acetone in which a defined amount of $\mathrm{MoO}_{3}$ powder was mixed well. To achieve stable dispersion of $\mathrm{MoO}_{3}$ powder in acetone, the ultrasonic vibration for 3 minutes was adapted. The container with the specimen was warmed up to $45{ }^{\circ} \mathrm{C}$ to evaporate acetone.

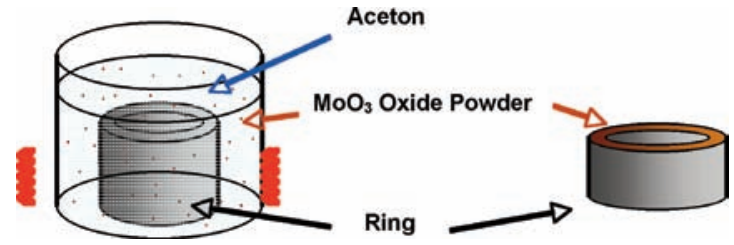

Fig. 3 Sample preparation procedure - coating

By this method finally the $\mathrm{MoO}_{3}$ powder was uniformly accumulated on the sliding surface of the stainless steel specimen. In this way prepared specimens were used as a $\mathrm{MoO}_{3}$ coated specimens. See Figs. 3 and 4.

3. The amount of accumulated $\mathrm{MoO}_{3}$ powder on the specimen nominal surface was estimated by measuring the weight of the specimen before and after coating treatment. An average mass of adherent powder was controlled to be between 5 and $6 \mathrm{mg}$.

Stainless steel was used as a ring specimen and some of them were coated with the $\mathrm{MoO}_{3}$ powder. The outer and inner diameter of the ring specimen was 20 and $15 \mathrm{~mm}$, respectively.
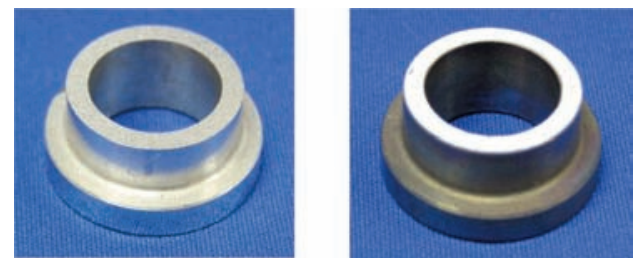

Fig. 4 Stainless steel ring specimen sandblasted uncoated and coated 
Aluminium bronze was used as a disk specimen and its thickness was about $5 \mathrm{~mm}$. Fig. 5 shows the form of an alloy rod and the prepared disc.

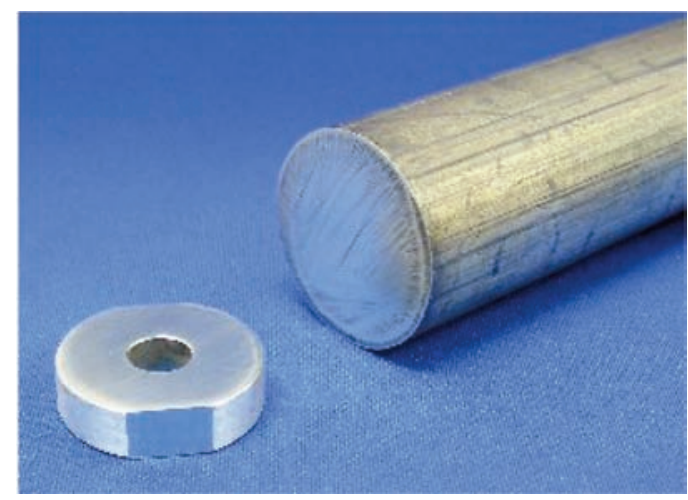

Fig. 5 Aluminium bronze disc specimen uncoated

\section{Friction Test}

To perform the friction test the ring-on-disk tribometer with a furnace in which the ring and disk specimens were mounted was used. The common load for all the experiment was set at $61.8 \mathrm{~N}$ which evocated to the median contact pressure of $0.46 \mathrm{MPa}$ at the nominal surface of ring and disc. The ring specimen rotated at $60 \mathrm{rpm}$ so the speed corresponded to the sliding speed of $55 \mathrm{~mm} / \mathrm{s}$. During performed experiments the approximate sliding distance reached about $200 \mathrm{~m}$. For each temperature range starting at the room temperature (R.T.) and increasing step by step up to $700{ }^{\circ} \mathrm{C}$ new specimens were used. In this way the initial conditions for testing the high temperature lubrication ability of the coating remained the same for the whole experimental work. The tribometer was thoroughly described in [6, 7]. Figure 6 shows the plotted friction coefficient for the uncoated and coated specimens. It can be seen that the friction coefficient in the case of uncoated pair steadily increased from values around 0.25 to values of 0.72 cor- responding to the increase of temperature from R.T. to $600^{\circ} \mathrm{C}$. By reaching the temperature of $700{ }^{\circ} \mathrm{C}$ the test was terminated because friction force exceeded the upper limit of this tribometer. The trend of the friction coefficient curve for the pair represented by $\mathrm{MoO}_{3}$ coated stainless steel specimen and aluminium bronze can be divided into two different parts. The first part is characterised by a steady increase of values of the friction coefficient starting from 0.19 to 0.56 well corresponding to the increase of the temperature from R.T. to $400{ }^{\circ} \mathrm{C}$. The second part is characterised trough a decrease of the coefficient of friction to the level of 0.44 with increase of the temperature up to $600{ }^{\circ} \mathrm{C}$, followed by an increase of the friction coefficient again to the value of 0.57 by increasing temperature to $700{ }^{\circ} \mathrm{C}$. This increase of the coefficient of friction around the $700{ }^{\circ} \mathrm{C}$ can be partly seen as the influence of beginning $\mathrm{MoO}_{3}$ sublimation.

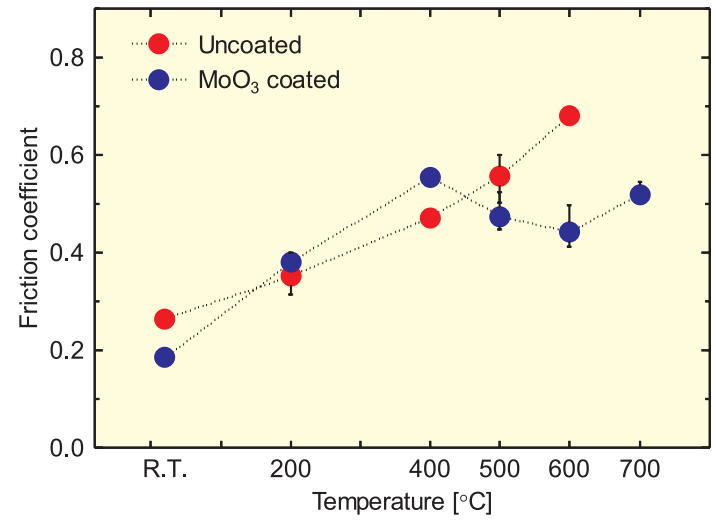

Fig. 6 Friction coefficient for the aluminium bronze disk and coated and uncoated $\mathrm{MoO}_{3}$ stainless steel ring

From Figs. 7 and 8 the difference of adhesion appearing can be clearly seen. While for uncoated surfaces of both specimens a large amount of adhesion was observed (started at temperatures around $400{ }^{\circ} \mathrm{C}$ ) for the $\mathrm{MoO}_{3}$ coated stainless steel ring a large adhesion was observed only at temperature of $400{ }^{\circ} \mathrm{C}$.
R.T.
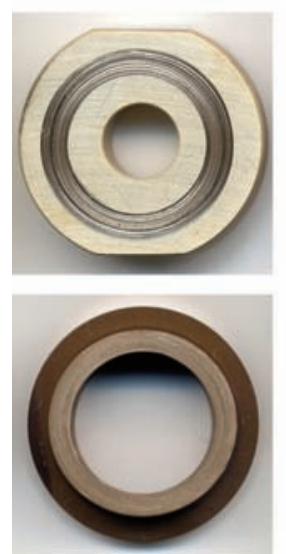

$200^{\circ} \mathrm{C}$
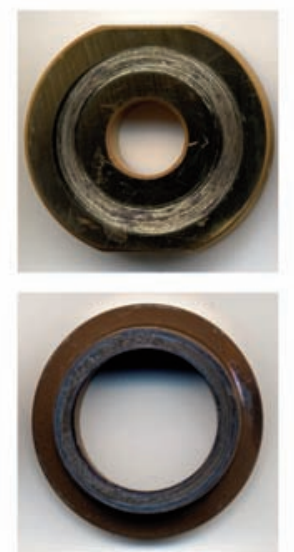

$400^{\circ} \mathrm{C}$
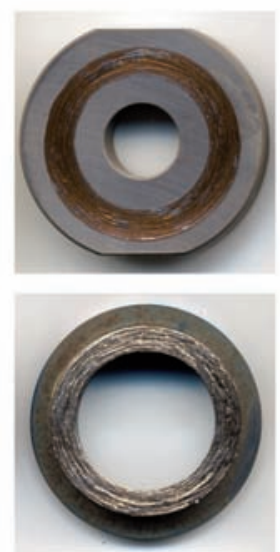

$500^{\circ} \mathrm{C}$

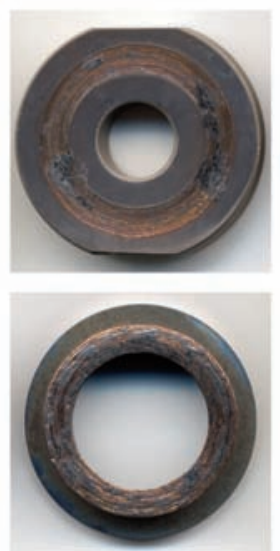

$600^{\circ} \mathrm{C}$

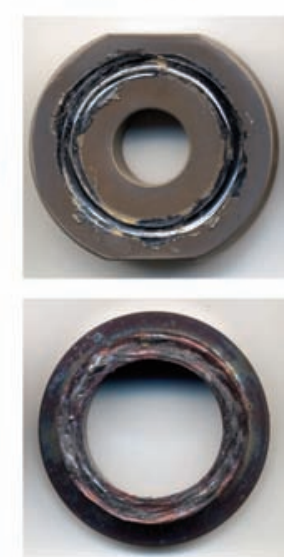

Fig. 7 Uncoated sliding surfaces of stainless steel ring and aluminium bronze disk after experiments at different temperatures 
R.T.
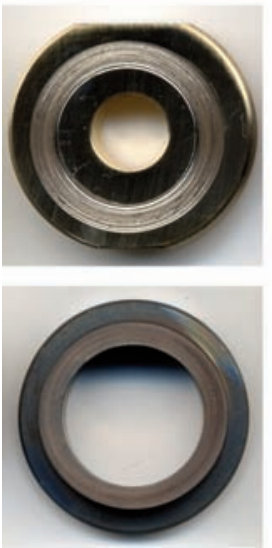

$200^{\circ} \mathrm{C}$
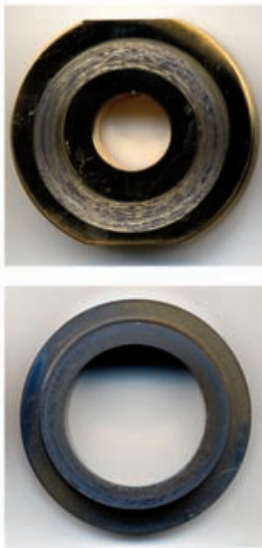

$400^{\circ} \mathrm{C}$
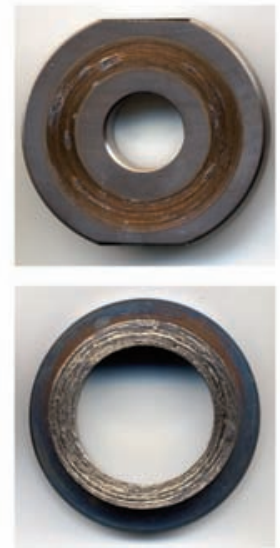

$500^{\circ} \mathrm{C}$
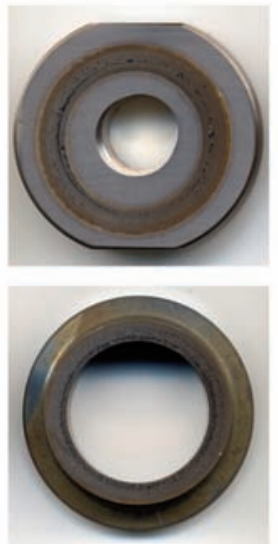

$600^{\circ} \mathrm{C}$
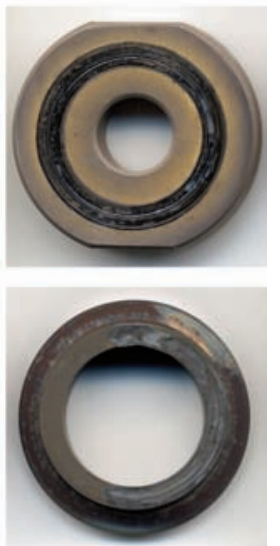

Fig. $8 \mathrm{MoO}_{3}$ powder coated sliding surfaces of stainless steel ring and aluminium bronze disk after experiments at different temperatures

\section{X-ray Diffraction Analysis}

For better understanding of friction and lubrication processes realised inside the contacted areas the XRD (X-ray diffraction) analysis was used. Some of the obtained results of the friction track on the aluminium bronze disk specimen, pressed and rubbed against the stainless steel ring coated with $\mathrm{MoO}_{3}$, are presented in Fig. 9.

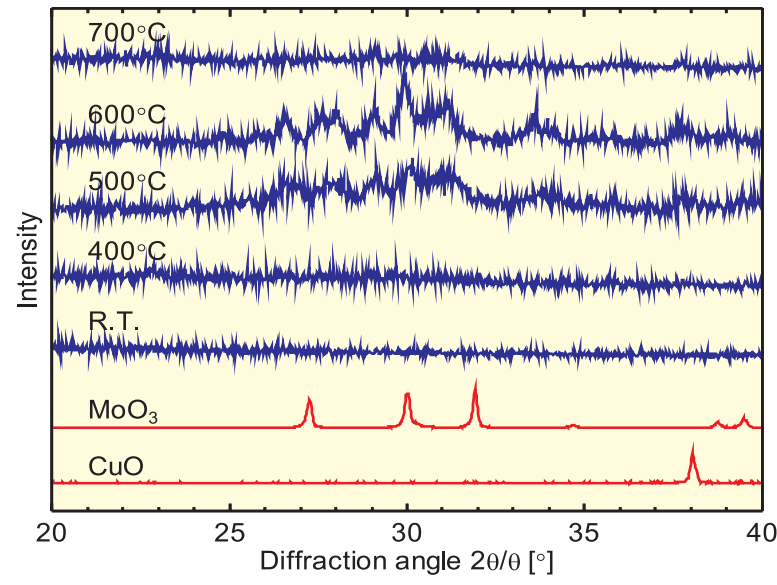

Fig. 9 XRD spectra obtained from the friction track resulting from temperatures R.T. to $700{ }^{\circ} \mathrm{C}$ of the aluminium bronze rubbed against $\mathrm{MoO}_{3}$ coated stainless steel ring, for $\mathrm{MoO}_{3}$ powder and for $\mathrm{CuO}$ powder

The diffraction peaks obtained from $\mathrm{MoO}_{3}$ powder and $\mathrm{CuO}$ powder are also shown in the same figure as reference. To obtain significant data cobalt target X-ray source was chosen. This was necessary because aluminium bronze contains a few $\%$ irons as indicated in Table 2. In this range of diffraction angle, no peak of aluminium bronze could be registered. The analysis of specimen used and tested at higher temperatures of 500 and $600{ }^{\circ} \mathrm{C}$ shows several peaks with certain intensity. Fig. 9 shows that similar peaks are obtained also from the specimens tested at $700{ }^{\circ} \mathrm{C}$, though the diffraction intensity is small. This comparison with the diffraction peaks obtained from $\mathrm{MoO}_{3}$ and $\mathrm{CuO}$ powder leads to the conclusion that the peaks obtained from the friction track on the aluminium bronze are not resulting directly from $\mathrm{MoO}_{3}$ or $\mathrm{CuO}$ powders.

In our previous work $[6,7]$ we conducted peak identification with the diffraction peak intensity in the database. The XRD spectrum obtained from the friction track of aluminium bronze slid against the $\mathrm{MoO}_{3}$ coated ring at $600{ }^{\circ} \mathrm{C}$ and the diffraction peak intensity of $\mathrm{Cu}_{3} \mathrm{Mo}_{2} \mathrm{O}_{9}$ in the database (JCPDS 01-070-1495) were compared. It can be suggested that the emerged material on the friction track of aluminium bronze is $\mathrm{Cu}_{3} \mathrm{Mo}_{2} \mathrm{O}_{9}$ because the diffraction peak position and intensity of database are in good agreement with the obtained XRD spectrum. This can indicate selective transfer of interacting elements during tribological process at high temperatures. Also it can be considered that $\mathrm{MoO}_{3}$ reduced friction of the tested pair by changing into $\mathrm{Cu}_{3} \mathrm{Mo}_{2} \mathrm{O}_{9}$. Wahl et al. reported [8] that the ion-beam deposited amorphous $\mathrm{Cu}-\mathrm{Mo}$ coating on alumina substrates showed low friction coefficient at 530 and $650{ }^{\circ} \mathrm{C}$. They suggested that the amorphous $\mathrm{Cu}-\mathrm{Mo}$ coating changed to crystalline oxide $\mathrm{CuMoO}_{4}$ and that the softened oxides worked as high temperature lubricant. Though $\mathrm{Cu}_{3} \mathrm{Mo}_{2} \mathrm{O}_{9}$ has different crystal structure from $\mathrm{CuMoO}_{4}$, it is possible that $\mathrm{Cu}_{3} \mathrm{Mo}_{2} \mathrm{O}_{9}$ having similar ingredient with $\mathrm{CuMoO}_{4}$ is softened and shows superior lubricity at high temperature.

\section{Conclusions}

Molybdenum trioxide $\mathrm{MoO}_{3}$ powder in the form of an adhered layer supplied to the sliding interface between aluminium bronze and stainless steel reduced the friction coefficient of both materials at high temperature. The effect of abrasion and adhesion shifted to the temperature range of 500 and $600{ }^{\circ} \mathrm{C}$. Copper-molybdenum oxide, which was supposed to be $\mathrm{Cu}_{3} \mathrm{Mo}_{2} \mathrm{O}_{9}$, was generated during the tribological contact process by sliding aluminium bronze and stainless steel in presence of $\mathrm{MoO}_{3}$ powder. 


\section{Acknowledgement}

This work was carried out under the support of The Ministry of Education, Culture, Sports, Science and Technology (MEXT), Japan. Grant-in-Aid for Young Scientists (B): 21760112 and by VEGA project V08-036-00 of the Ministry of Education, Slovak Republic.
Exchanges were realised with the support of the National scholarship scheme of the Ministry of Education and Slovak Academic Information Agency SAIA, s.r.o. Slovak Republic.

The authors wish to thank Mrs. Naoki Okamoto, and Mr. Takashi Chujyo, Masao Uemura, Ivan Havetta, Hirotomo Kobayashi for their support during the intensive experimental work.

\section{References}

[1] PETERSON, M. B., MURRAY, S. F., FLOREK, J. J.: Consideration of Lubricants for Temperatures above $1000{ }^{\circ} \mathrm{F}$, ASLE Trans., 2/1960, 225-234.

[2] http://en.wikipedia.org/wiki/Molybdenum trioxide (02.02.2010)

[3] HEYNES, J. B. B.; CRUYWAGEN, J. J.: Yellow Molybdenum(VI) Oxide Dihydrate, Inorganic Syntheses, 1986, vol. 24 , pp. 191. ISBN 0-471-83441-6

[4] WELLS, A.F.: Structural Inorganic Chemistry, Oxford: Clarendon Press, ISBN 0-19-855370-6, (1984)

[5] http://www.chinatungsten.com/Molybdenum/Molybdenum-Trioxide.html (02.20.2010)

[6] PETERSON, M. B., MURRAY, S. F., FLOREK, J. J.: Consideration of Lubricants for Temperatures above $1000^{\circ} \mathrm{F}$, ASLE Trans., 2/1960 225-234.

[7] TAKEICHI, Y., CHUJYO, T., OKAMOTO, N., HAVETTA, I., DZIMKO, M., UEMURA, M.: Wear and Frictional Properties of Aluminium Bronze Alloy Lubricated with Molybdenum Trioxide at High Temperature, Synopsis of 17th International Colloquium Tribology in Esslingen 2010, ISBN-Nr. 3-924813-80-9

[8] TAKEICHI, Y., CHUJYO, T., OKAMOTO, N., UEMURA, M.: Effects of Molybdenum Trioxide on the Tribological Properties of Aluminium Bronze under High Temperature Conditions, Japanese Society of Tribologists, Japan Tribology Online, vol. 4, 5/2009, pp. 135-139

[9] WAHL, K. J., SEITZMAN, L. E, BOLSTER, R. N., SINGER, I. L., PETERSON, M. B.: Ion-Beam Deposited Cu-Mo Coatings as High Temperature Solid Lubricants, Surface and Coating Technology, 89/1997, 245-251. 